\title{
A Study of Sports Related Occurrence of Traumatic Orodental Injuries and Associated Risk Factors in High School Students in North India
}

\author{
Gundeep Singh ${ }^{1}$; Shalini Garg ${ }^{1,2, *}$; Satyawan Gangaramji Damle ${ }^{1}$; Abhishek Dhindsa ${ }^{1}$; \\ Ambreen Kaur ${ }^{3}$; Shilpy Singla ${ }^{2}$
}

${ }_{2}^{1}$ M. M. College of Dental Sciences and Research, Maharishi Markandeshwar University, Mullana-Ambala, India

${ }_{3}^{2}$ Department of Pediatric and Preventive Dentistry, People's College of Dental Sciences, Bhanpur Road, Bhopal, India

3 Private Practitioner, Patiala, India

${ }^{*}$ Corresponding author: Shalini Garg, M. M. College of Dental Sciences and Research, Maharishi Markandeshwar University, Mullana-Ambala, Haryana, India. Tel: +91-9215668621, Fax:+91-1731274325, E-mail: shaloosandeep@gmail.com

Received: July 15, 2013; Accepted: March 5, 2014

\begin{abstract}
Background: Oral and dental injuries contribute to a major part of sports related injuries in children. Trauma occurring in developing years disrupts normal social functioning and brings about a major impact on quality of life due to their cumulative effect.

Objectives: To assess the prevalence and causes of various sports related traumatic orodental injuries among 8 to 16 year school students along with identifying the associated risk factors in North India.

Patients and Methods: A cross sectional study consisting of high school students of different organized sports teams aged 8-16 years was carried out in geographical area of north India. The students were selected by multistage cluster sampling methodology. 1105 students from 19 school teams (sports teams) and sports academies participated in study through structured interview and clinical examination in different sports situations.

Results:30.3\% ( $n=335)$ of students suffered from orodental injuries. A higher number of girls had injury(32\%) than boys (29\%), though the difference was not significant. Most of the students suffered from soft tissue injuries (48\%) followed by tooth fractures (43\%). Maximum numbers of injuries were reported in high velocity (44.1\%) and medium intensity sports $(46.6 \%)(\mathrm{P}<0.001)$ Maximum injuries occurred in basketball (50\%) and lowest in the field of badminton $(6.1 \%)(\mathrm{P}<0.05)$. Amateurs $(52 \%)$ suffered the most from injuries as per level of coaching. Only $6 \%$ of boys and $2 \%$ of girls used mouthguards.

Conclusions: The result of the present study confirmed that students participating in different organized sports at high school level are at a very high risk of getting orodental injury. Hence knowledge and education regarding prevention of traumatic injuries is of paramount importance.
\end{abstract}

Keywords:Athletic Injuries; Tooth Fractures; Sports

\section{Background}

Oral and dental injuries contribute to a major part of sports related injuries in children. Trauma occurring in developing years disrupts normal social functioning and brings about a major impact on quality of life due to their cumulative effect. Determining occurrence of trau$\mathrm{ma}$ is the first step in providing prevention measures and programs. A significant number of oral and dental injuries result from participation in contact sports (sports in which children physically interact with each other, trying to prevent the opposing team or person from winning) and other organized sports (1). According to the International Academy for Sports Dentistry the main goals of sports dentistry include prevention and treatment of sports related dental/orodental injuries, information collection, information dissemination and promotion of research on the preventive procedures related to injuries of such a specific etiology $(2,3)$. The risk of oral and dental trauma in contact sporting activities was assessed in the 1980s as being higher than the risk of such injuries sustained during children's play or the risk related to non-contact sporting activities, the role of the dental profession then became very important $(4,5)$. In a developing country like India, where economic constraints cannot be neglected, the need of knowledge of health economics is even more important as a basis for judging health gain in curative and preventive care. The best prevention of dental and oral injuries is probably education, both how to avoid injuries as well as how to manage them at the site of the injury when they occur. This education should be targeted equally at children, teenagers and those who are around them, their parents, school sports authorities and coaches, when they are at risk of injuring themselves. During sports activities where there is a risk of fall or being hit by an object, wearing a mouth guard or faceguard still seems to be only way to prevent or at least significantly reduce the seriousness of dental injuries. Children/students playing sports are not aware of the health implications of 
a traumatic injury to the mouth or of the potential for incurring severe head and orodental injuries while playing. The dentist can play an imperative role in informing athletes, coaches and patients about the importance of preventing orodental injuries in sports. Most of the literature about occurrence of injuries is available from industrialized nations whereas from a developing country like India, data is scarce.

\section{Objectives}

This study was conducted to assess the occurrence of orodental injuries and associated risk factors amongst high school children/students in various organized sports situations.

\section{Patients and Methods}

\subsection{Study Population and Sampling Procedure}

A cross sectional study consisting of high school students of different organized sports teams among age 8-16 years was conducted in the geographical area of North India through interview and clinical examination. Prior permission for study was taken from Deputy Director Sports authority of Haryana state, administrative officers of sports academies and respective school authorities. Study was approved by ethical committee of University. Multistage cluster sampling procedure was used to select students from a total of 25680 high school students from 19 schools from a geographical area of 5 major cities, of North India. As the number of high school students differed in the 5 cities according to total population of that city, a greater number of sports students from the city with higher number of students participated in study and vice versa. Simple random samples of 1117 students finally were considered in study from a total of 3506 students playing different organized sports. 12 students who had history of orodental trauma with reason other than sports injury were excluded from the study. So, finally, 1105 students were subjected to result analysis in the present study. Participation of students was voluntary and an informed consent letter was taken after giving complete information about the study to all students of teams and their coaches. An interview based questionnaire with examination form was distributed to students who voluntarily participated in the study to know about their personal details and games they play. Questions 1-13 involved personal details and history related information and points 14-22 were for examination based records. The examination of all the study subjects was carried out in natural light using a mouth mirror and blunt probe and findings were recorded on a predesigned format. Assessment of risk factors pertaining to type of malocclusion, over jet and lip competency was done. All the sports commonly played in this region were included in the question- naire. Other groups included games like volleyball, cycling, wrestling, judo, karate, martial arts, athletics etc. The classification given by Mitchell et al. was considered to categorize the type of sports, according to low moderate and high static and dynamic components indicating intensity and velocity of respective sports (6). Types of oral and dental injuries were recorded in terms of soft tissue injuries tooth fractures, tooth discoloration, lateral dislocations and avulsion by history taking and examination. Pulp sensitivity tests and radiographic examinations were not performed during this study so root fractures were not recorded.

SPSS version 10 was used for data analysis. Chi square tests were applied to carry out statistical significance. The level of significance set was $\mathrm{P}<0.005$.

\section{Results}

1105 students from 19 organized sports school teams with mean age of $12.4 \pm 3.5$ years participated in the study. 714 (64.6\%) were boys, and 391 (35.4\%) were girls. In response to the question: "have you ever suffered from orodental injury" 335 (30.3\%) answered yes and 770 answered no. A higher number of girls had injury (32\%) than boys (29\%), though the difference was not significant. Most of players suffered from soft tissue injuries (48.1\%) followed by tooth fractures (43\%) followed by tooth discoloration (6.3\%), lateral dislocations (1.5\%) and avulsion (1.2\%). The difference was highly significant $(\mathrm{P}<0.05)$ (Figure 1 ).

The highest percentage of injuries, within respective groups was reported in basketball (50\%) followed by skating (41.8\%), other group (41.2\%), cricket (26.3\%), handball (25\%), hockey (23.5), football (10.5\%) and minimum in badminton (6.1\%) (Table 1, Figure 2). The difference was statistically significant $(\mathrm{P}<0.05)$. Various high risk sports constituting, other group, reported with very high percentage of injuries like wrestling (75\%), cycling (67.6\%) taekwondo (55.5\%), khokho (54.9\%), swimming (40\%), volleyball (40\%), karate (37.5\%), judo (31.3\%), boxing (29.1\%), table tennis (26.9\%), athletics (20.5\%), etc. (Table 2 ).

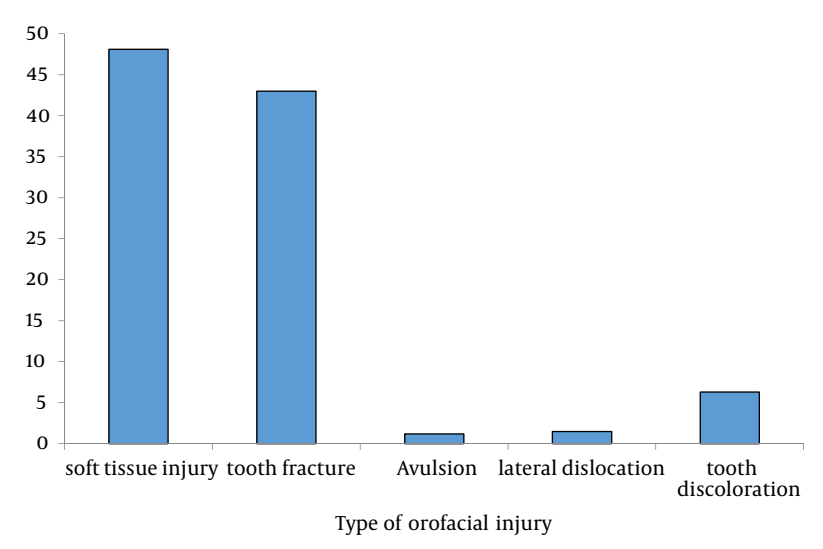

Figure 1. Distribution of Type of Orodental Injury 
Maximum numbers of injuries were reported in high velocity (44.1\%) and medium intensity sports (46.6\%) followed by low intensity (30.7\%) and medium velocity. Most of the injuries occurred during game (54.9\%) as compared to practice sessions (45.1\%) but the difference was not statistically significant. Regarding risk factors, most of the injuries (52\%) occurred in students with overjet more than $4 \mathrm{~mm}$. A large number of the orodental injuries occurred in subjects with incompetent lips (24.3\%). The difference was not statistically significant ( $P$ $>0.05)$. More injuries were reported by mouth breathers $(23.8 \%)$ though the difference was not statistically significant. Only $2.7 \%$ of the subjects with orodental injuries

Table 1. Frequency and Distribution of Examined Children and Sports Related Injuries According to Sports ${ }^{a}$

\begin{tabular}{lccc}
\hline Sport & Individuals & $\begin{array}{c}\text { Oro Dental } \\
\text { Trauma }\end{array}$ & $\begin{array}{c}\text { Age Within } \\
\text { the Group, \% }\end{array}$ \\
\hline Basketball & $110(10.0)$ & $55(16.4)$ & 50 \\
Handball & $112(10.1)$ & $28(8.4)$ & 25 \\
Badminton & $97(8.8)$ & $6(1.8)$ & 6.1 \\
Hockey & $123(11.1)$ & $29(8.7)$ & 23.5 \\
Football & $95(8.6)$ & $10(3)$ & 10.5 \\
Skating & $74(6.7)$ & $31(9.3)$ & 41.8 \\
Cricket & $186(16.8)$ & $49(14.6)$ & 26.3 \\
Others & $308(27.8)$ & $127(37.8)$ & 41.2 \\
\hline
\end{tabular}

a Values are presented as No. (\%).

Table 2. Frequency and Distribution of Examined Children and Sports Related Injuries in Others Sports Category ${ }^{a}$

\begin{tabular}{lccc}
\hline Others & Individuals & $\begin{array}{c}\text { Oro dental } \\
\text { trauma }\end{array}$ & $\begin{array}{c}\text { Age Within } \\
\text { Group, \% }\end{array}$ \\
\hline Athletics & $39(3.5)$ & $8(2.4)$ & 20.5 \\
Swimming & $5(0.5)$ & $2(0.6)$ & 40 \\
Kho-Kho & $51(4.6)$ & $24(8.4)$ & 54.9 \\
Gymnastics & $9(0.8)$ & $1(0.3)$ & 11.1 \\
\hline Judo & $16(1.4)$ & $5(1.5)$ & 31.25 \\
Kabaddi & $17(1.5)$ & $2(0.6)$ & 11.7 \\
Karate & $8(0.7)$ & $3(0.9)$ & 37.5 \\
Martial Arts & $4(0.4)$ & $0(0)$ & 0 \\
Taekwondo & $9(0.8)$ & $5(1.5)$ & 55.5 \\
Volleyball & $25(2.3)$ & $10(3)$ & 40 \\
TennisTennis & $26(2.4)$ & $7(2.1)$ & 26.9 \\
\hline Softball & $3(0.3)$ & $0(0)$ & 0 \\
\hline Wrestling & $4(0.4)$ & $3(0.9)$ & 75 \\
Boxing & $24(2.2)$ & $7(2.1)$ & 29.1 \\
\hline Bicycling & $68(6.2)$ & $46(13.7)$ & 67.6 \\
\hline Total & $308(27.8)$ & $127(37.8)$ & 41.2 \\
\hline Valusare & & &
\end{tabular}

a Values are presented as No. (\%). were having orthodontic treatment done at the time of study. Out of this $42.8 \%$ (9/21) suffered from orodental injuries. The difference was significant $(\mathrm{P}<0.05)$. The injuries occurred signifi $\neg$ cantly in students with Angle Class II div 1 relation (38.8\%) followed by class I type 2 (23.9\%) relation $(\mathrm{P}=0.014)$ (Table 3$)$. In our study the highest number of students were juniors (76.8\%), followed by amateurs (21.8\%), semiprofessionals (1\%) and professionals $(0.4 \%)$ as per level of coaching. Amateurs (52\%) suffered the most injuries as compared to juniors (25\%) (P $<0.05$ ) (Table 4). Only $511(46.2 \%)$ of the students knew about the mouth guards. Only $6 \%$ of boys and $2 \%$ of girls used mouth guards.

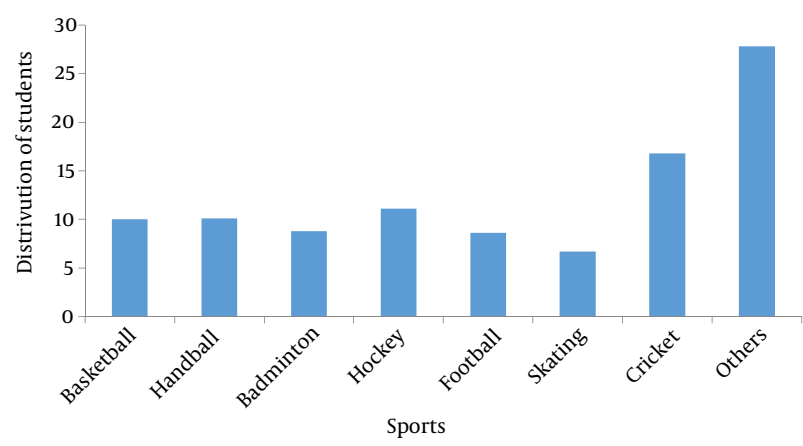

Figure 2. Graph Showing Distribution of Students According to Their Sports and Depicting Their Participation According to Velocity and Intensity of Sports

Table 3. Risk Factors Associated With Sports Related Injuries

\begin{tabular}{|lcc}
\hline Risk Factors & $\begin{array}{c}\text { Suffered From } \\
\text { Injury }\end{array}$ & Total \\
\hline Overjet, mm & $106(18.8)$ & 562 \\
\hline$<2$ & $38(21.6)$ & 176 \\
\hline $2-4$ & $191(52)$ & 367 \\
\hline$>4$ & 335 & 1105 \\
\hline Total & $27(24.3)$ & 110 \\
\hline Incompetent lips & $15(23.8)$ & 63 \\
\hline Mouth breathing habit & $9(42.8)$ & 21 \\
\hline $\begin{array}{l}\text { Subjects with fixed } \\
\text { orthodontic treatment }\end{array}$ & & \\
\hline
\end{tabular}

Type of Malocclusion

\begin{tabular}{lcc} 
CI,T2 & $80(23.9)$ & 177 \\
CII,D1 & $130(38.8)$ & 247 \\
Others & $125(37.3)$ & 681 \\
Total & 335 & 1105 \\
\hline
\end{tabular}

a Values are presented as No.(\%). 
Table 4. Distribution of Children and Injury According to Their Level of Coaching ${ }^{\mathrm{a}}$

\begin{tabular}{lccc}
\hline \multirow{2}{*}{$\begin{array}{l}\text { Level of Coach- } \\
\text { ing }\end{array}$} & \multicolumn{2}{l}{ Suffered From Injury } & \multirow{2}{*}{ Total Participant } \\
\cline { 2 - 3 } & Yes & No & \\
\hline Juniors & $210(25)$ & 640 & $850(77)$ \\
Amateurs & $124(52)$ & 116 & $240(21.8)$ \\
$\begin{array}{l}\text { Semiprofes- } \\
\text { sionals }\end{array}$ & None & 11 & $11(1.0)$ \\
Professionals & $1(25)$ & 3 & $4(0.4)$ \\
\hline Total & 335 & 770 & 1105 \\
\hline a Values are presented as No. (\%). & &
\end{tabular}

\section{Discussion}

A total of 1105 students from various sports academies and high schools participated in the present study. The present study identifies an occurrence rate of $30.3 \%$ of orodental injuries in students participating in organized sports i.e. high risk group (sports in which children physically interact with each other, trying to prevent the opposing team or person from winning). More girls had injury (32\%) than boys (29\%), though the difference was not significant. Sports have been reported to be associated with high occurrence of orodental injuries. Prevalence of dental trauma reported in Pan America games athletes was $49.6 \%$, with no gender-based differences (7). $50 \%$ of athletes sustained orofacial injuries in Brazilian basketball players (8). Study regarding traumatic injuries to anterior teeth in south Indian students reported that $34 \%$ injuries were due to sports related accidents (9).

Maximum numbers of injuries were reported in high velocity (44.1\%) \& medium intensity sports (46.6\%). According to type of injury most number of students suffered from soft tissue injuries (48.1\%) followed by tooth fractures (43\%). Dental injuries are mainly caused by hits to the facial area with the racket or by collision with the opponent because of high velocity and close contact. Because of the rapid impulse of the impacting force, the injury mechanism results in direct trauma, which is conductive to a crown fracture (10). According to Frontera et al.'s study regarding orofacial trauma in Brazilian basketball players, dental trauma accounted for 69.7\%, with emphasis on maxillary central incisors, followed by soft tissue (60.8\%), in which lip injuries were the most prevalent (8). The present study reported highest percentage of injuries in basketball (50\%) followed by skating (41.8\%) and other group (41.2\%). Various high risk sports constituted other group (6).

Significantly high occurrence of orodental injuries in the other group was in wrestling (75\%) and cycling (67.6\%). Andrade et al. reported highest prevalence of dental trauma in wrestling (83.3\%) followed by boxing (73.7\%) and basketball (70.6\%). It has been reported in literature that bicycling causes significantly higher rates of crown fractures than other types of sports (7). In a study of maxillofacial injury in students under 15 years of age in southern China bicycle accidents were the leading cause of dental facial injuries (11). Most of the injuries occurred during game (54.9\%) as compared to practice sessions (45.1\%). This is in agreement with study by Sane et al. in which they found that $69 \%$ of all injuries occurred during matches, compared with $31 \%$ during training sessions (12).

Most of the injuries in this study occurred in students with overjet $>4 \mathrm{~mm}$ (52\%) and incompetent lip (24.3\%). Previous studies have also reported a relationship between incisor trauma and both over-jet and lip incompetence (13-16). The findings in this study revealed increased over-jet to be associated with incisor injury but found no significant relation between incisor injury and inadequate lip coverage. Most of the injuries occurred in students with Angle Class II div 1 relation (38.8\%) followed by class I type $2(23.9 \%)$ relation. Patients with Angle's class II div I malocclusion would make any facial trauma dentally dangerous to the patient. Such patients are at risk from a variety of normal physical circumstances that would not necessarily be risk factors for Angle's class I patients $(17,18)$.

$42.8 \%$ have suffered from orodental injuries with orthodontic therapy in the present study. The orthodontic appliances may injure the lips and cheeks and a mouth guard may prevent laceration and bruising of the lips and checks during impact. Amateurs (52\%) suffered the most from injuries as compared to juniors and professionals. Moreover, studies have shown that amateurs do hurt their opponents because of less experience and bad techniques. Also they suffer the most from racket injuries $(19,20)$. The reason why professionals have less dental trauma is their experience and the, let rule. Only 511 (46.2\%) of the students knew about the mouth guards. Only $6 \%$ of boys and $2 \%$ of girls used mouth guards. Relation of dental injuries to less knowledge and limited use of mouth guards has been reported in most of the studies. Spinas et al. reported that only $1 \%$ of children participating in sports activities wore a mouth guard during practice (21).

It is observed that use of mouth guards is not necessary as per rules in high risk contact sports like basketball, handball, football, baseball and judo nor low risk contact sports like biking, volleyball, skating (7). Therefore young students should receive special attention for sports injuries prevention. They should be educated about dental trauma along with those who care for them, especially those who are responsible for their safety during school and organized activities. A simple instruction sheet explaining do/do not in many cases is more than sufficient to ensure that those who are informed receive proper use of preventive measures and emergency care at the site of the injury. In conclusion, initial planning to manage and prevent these orodental injuries has to be dealt differently for different sports in different age groups of students. Each study presents a customized result as per geo- 
graphical areas making it impossible to generalize the results on a broader scale. As do all studies, this study also had limitations. Only high school teams affiliated to state sports authority were included. As all sports students, practices and competitions could not be attended during the study, limiting participation and a small number of injuries in certain stratifications may have prevented some findings from being statistically significant. Patterns and severity of injuries could not be well described. Despite these limitations, specifically including high school teams playing organized sports and data collection of oral and dental injuries by a pediatric dentist in individual sport, this study expands upon the previous knowledge base.

Epidemiological research is the fundamental first step in the sequence of prevention. Due to the geographic representativeness and sport specification, this study speaks to the fact that identifying ways to prevent individual sport related injuries should be a priority in students.

The present study highlights the need for injury prevention and management education at school level as soon as student become a part of a team. Sport-specific studies identifying activities with high injury risk can help in developing targeted training techniques or protective equipment interventions to lower injury rates in developing years. Schools and sports academies need to ensure that coaches are qualified and up to date on the appropriate techniques of individual sport for teaching students the skills that yield the best performance while maintaining the highest possible level of safety.

\section{Acknowledgements}

We are highly thankful to the administration, coaches and students of the following academies: NIS, Patiala; Chandigarh Football and Hockey academy, Chandigarh; SD Skating ring, Karnal; Hockey academy, Shahbad; Police DAV Cricket academy, Ambala.

\section{Authors' Contributions}

Concept/Design: Gundeep Singh, Shalini Garg. Acquisition of Data: Gundeep Singh, Shalini Garg. Data Analysis/ Interpretation: Gundeep Singh, Shalini Garg. Manuscript Preparation: Satyawan Gangaramji Damle, Abhishek Dhindsa, Ambreen Kaur, Shilpy Singla. Approval of the Article: Gundeep Singh, Shalini Garg, Satyawan Gangaramji Damle, Abhishek Dhindsa, Ambreen Kaur, Shilpy Singla.

\section{References}

1. Andreasen JO, Andreasen FM. Textbook and Colour Atlas of Traumatic Injuries tothe Teeth.: Wiley; 2001.

2. Demas PN. Surgical management of sports-related traumatic injuries. Dent Clin North Am. 2000;44(1):137-59.

3. Bejeh-Mir KP, Bejeh-Mir AP. Children dental trauma facts for emergent field management. Asian J Sports Med. 2012;3(1):64.

4. Ranalli DN. Sports dentistry and dental traumatology. Dent Traumatol. 2002;18(5):231-6.

5. Kumamoto DP, Maeda Y. A literature review of sports-related orofacial trauma. Gen Dent. 2004;52(3):270-80.

6. Mitchell JH, Maron BJ, Epstein SE. 16th Bethesda Conference: Cardiovascular abnormalities in the athlete: recommendations regarding eligibility for competition. October 3-5, 1984. J Am Coll Cardiol.1985;6(6):1186-232.

7. Andrade RA, Evans PL, Almeida AL, da Silva Jde J, Guedes AM, Guedes FR, et al. Prevalence of dental trauma in Pan American games athletes. Dent Traumatol. 2010;26(3):248-53.

8. Frontera RR, Zanin L, Ambrosano GM, Florio FM. Orofacial trauma in Brazilian basketball players and level of information concerning trauma and mouthguards. Dent Traumatol. 2011;27(3):208-16.

9. Rai SB, Munshi AK. Traumatic injuries to the anterior teeth among South Kanara school children--a prevalence study. J Indian Soc Pedod Prev Dent. 1998;16(2):44-51.

10. Petti S, Tarsitani G. Traumatic injuries to anterior teeth in Italian schoolchildren: prevalence and risk factors. Endod Dent Traumatol.1996;12(6):294-7.

11. Qing-Bin Z, Zhao-Qiang Z, Dan C, Yan Z. Epidemiology of maxillofacial injury in children under 15 years of age in southern China. Oral Surg Oral Med Oral Pathol Oral Radiol. 2013;115(4):436-41.

12. Sane J, Ylipaavalniemi P. Dental trauma in contact team sports. Endod Dent Traumatol.1988;4(4):164-9.

13. Perheentupa U, Laukkanen P, Veijola J, Joukamaa M, Jarvelin MR, Laitinen J, et al. Increased lifetime prevalence of dental trauma is associated with previous non-dental injuries, mental distress and high alcohol consumption. Dent Traumatol. 2001;17(1):10-6.

14. Persson LG, Kiliaridis S. Dental injuries, temporomandibular disorders, and caries in wrestlers. Scand JDent Res. 1994;102(6):367-71.

15. Fos PJ, Pinkham JR, Ranalli DN. Prediction of sports-related dental traumatic injuries. Dent Clin North Am. 2000;44(1):19-33.

16. Burden DJ. An investigation of the association between overjet size, lip coverage, and traumatic injury to maxillary incisors. Eur JOrthod.1995;17(6):513-7.

17. Biagi R, Cardarelli F, Butti AC, Salvato A. Sports-related dental injuries: knowledge of first aid and mouthguard use in a sample of Italian children and youngsters. EurJPaediatrDent. 2010;11(2):6670.

18. Prabhu A, Rao AP, Govindarajan M, Reddy V, Krishnakumar R, Kaliyamoorthy S. Attributes of dental trauma in a school population with active sports involvement. Asian J Sports Med. 2013;4(3):190-4.

19. Matalon V, Brin I, Moskovitz M, Ram D. Compliance of children and youngsters in the use of mouthguards. Dent Traumatol. 2008;24(4):462-7.

20. Borssen E, Holm AK. Traumatic dental injuries in a cohort of 16-year-olds in northern Sweden. Endod Dent Traumatol. 1997;13(6):276-80.

21. Spinas E, Savasta A. Prevention of traumatic dental lesions: cog nitive research on the role of mouthguards during sport activities in paediatric age. Eur J Paediatr Dent. 2007;8(4):193-8. 